\title{
JBS Haldane: an evolutionary geneticist not without controversy
}

\author{
Marc Woodbury-Smith ${ }^{1}$ \\ Published online: 6 March 2018 \\ (c) European Society of Human Genetics 2018
}

Popularizing Science - the life and work of JBS Haldane Author: Krishna Dronamraju

Published by: Oxford University Press

Year: 2017

ISBN: 9780199333929

Price: £26.49 \$34.95 (Hardcover) €31.78 £23.84

Marc Woodbury-Smith, Institute of Neuroscience, Newcastle University, UK

JBS Haldane made many scientific contributions, and is perhaps best remembered as a population geneticist, principally in relation to his work on natural selection in the early $20^{\text {th }}$ century. As Arthur C. Clarke suggested, "J.B.S. Haldane was perhaps the most brilliant science popularizer of his generation". This idea of Haldane as a communicator of science (and politics) is central to Krishna Dronamraju's thesis, reflected in the book title Popularizing Science. Dronamraju, is described on the dust jacket as, "one of the last living men to have worked personally with Haldane" and this book, part biography part scientific exposition, is an insight into Haldane's life and work as only Dronamraju could provide. Throughout the book Dronamraju blends his own reflections with observations of those who were close to Haldane, including family and colleagues, to present an in-depth portrait of Haldane, the individual. When such biographic information is combined with Dronamraju's own expertise in the field, the result is a book that provides the reader with a much more comprehensive portrayal of Haldane's scientific achievements than what a simple biography could hope to achieve.

Aspects of Haldane's early life are described in detail, as are his theoretical work in population genetics, and lesser known contributions to physiology and enzyme kinetics.
Dronamarju takes great care to accurately describe Haldane's political evolution, from the early experiences that grounded his move to Marxian socialism, to his membership of the communist party, and, later, his misguided defence of Lysenko's vernalization.

There really are no books with which to compare Popularizing Science. It is the first biography of Haldane that was published since the late 1960s, and its scope is vast. The important role that Haldane has played in scientific discovery, particularly in genetics, in itself, in my mind, provides a strong argument for positively endorsing this book. Above and beyond this, the book is truly engaging, written with a fondness and respect for the Haldane the person, and yet it still manages to come across as largely objective.

Given the vastness of the project, the organization of the work itself seems to have presented the greatest challenge to Dronamraju; the attempt to organize the book chronologically while dividing the chapters up by thematic areas confounded the logical flow that Dronamraju perhaps intended. Consequently, there is much movement back and forth between historical epochs even within individual chronologically defined chapters. However, this should certainly not deter the interested reader. Popularizing Science is an important text for scientists and historians alike. It serves those who are wishing to explore science from a historical viewpoint, those who are interested in the scientific principles set out by Haldane that remain relevant to those of us working in complex disorder genetics, and those who simply have a broad interest in population and evolutionary genetics. Learning about Haldane from a skilled writer who also has the necessary personal and scientific insight has been a valuable experience.
Marc Woodbury-Smith

Marc.Woodbury-Smith@newcastle.ac.uk

1 Institute of Neuroscience, Newcastle University, Newcastle upon Tyne, United Kingdom 